\title{
the Contact Reliability Analysis of Gear Rack Based on the Kriging and RSM Method
}

\author{
Hui Liu ${ }^{1, \text { a }}$, Wei-Min Cui ${ }^{2, b}$, Bo He ${ }^{3, \mathrm{c}}$, Xiang-Rui Gong ${ }^{4, \mathrm{~d}}$ \\ ${ }^{1}$ Northwestern Polytechnical University, Xi'an,China \\ ${ }^{2}$ Northwestern Polytechnical University, Xi'an,China \\ ${ }^{3}$ Northwestern Polytechnical University, Xi'an,China \\ ${ }^{4}$ Northwestern Polytechnical University, Xi'an,China \\ aliuhui-1991@163.com, ${ }^{b}$ cuiwm.nwpu.edu.cn, chebo2009@126.com, ${ }^{d}$ gxrui1991@163.com
}

Keywords: gear rack; Kriging; response surface method

\begin{abstract}
Obtaining the peformance function of gear contact is difficult,and this paper founded the response surface model and the Kriging model with the usage of response surface and Kriging method.Then the reliability was calculated by the founded metamodel using Monte Carlo method.The result shows the kriging method owns a better accuracy than response surface method in numerical fitting.
\end{abstract}

\section{Introduction}

The gear rack is widely used in engineering,including steering mechanism, feeding mechanism of machine tool, wing flap,etc.It usually bear vast loads,causing failure mode of gear teeth snap,tooth surface wear, teeth surface pitting and tooth face agglutination.Accordingly,it is of high engineering usage value to analyze loading condition of gear rack,check the strength of contact area,and propose reliability accessment method.

The traditional designing method has been used until now but it can not actually reflect the objective situation without considering the uncertainty of the item. There are lots of blindness and experience in it

This paper will redesign the variable and change them into random variable, which will obey the probability distribution.Then the model of gear rack was established and performance function was founded by surrogate model of Kriging method and response surface method.The results was compared after reliability was calculated by Monte Carlo method and referential experiences were concluded.

\section{Finite Element Analysis of Gear Pair}

\subsection{Geometry Model of Gear Pair}

The material of gear rack is isotropic material of 20CrMnTi with the yield strength of 835MPa, elasticity modulus of $207 \mathrm{Gpa}$,and the poisson ratio of 0.3 . The parameter of gear rack is shown in Table 1.

Table 1 the parameters of gear rack

\begin{tabular}{cccc}
\hline & module[m] & number of teeth & Pressure angle[o] \\
\hline gear & 6 & 24 & 20 \\
rack & 6 & 23 & 20 \\
\hline
\end{tabular}

\subsection{The Finite Element Model of Gear Pair}

The net is divided in abaqus using C3D10.The net of contact area is specially intense,which is shown in Fig. 1. 


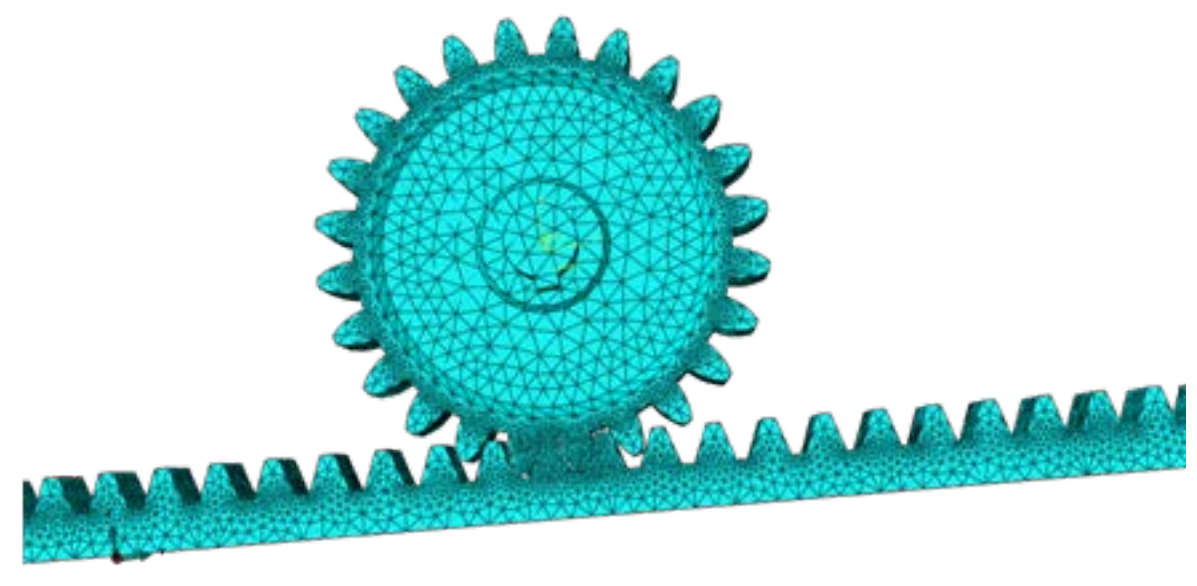

Figure 1 gear rack net division

The Mises stress nephogram is shown in Fig. 2

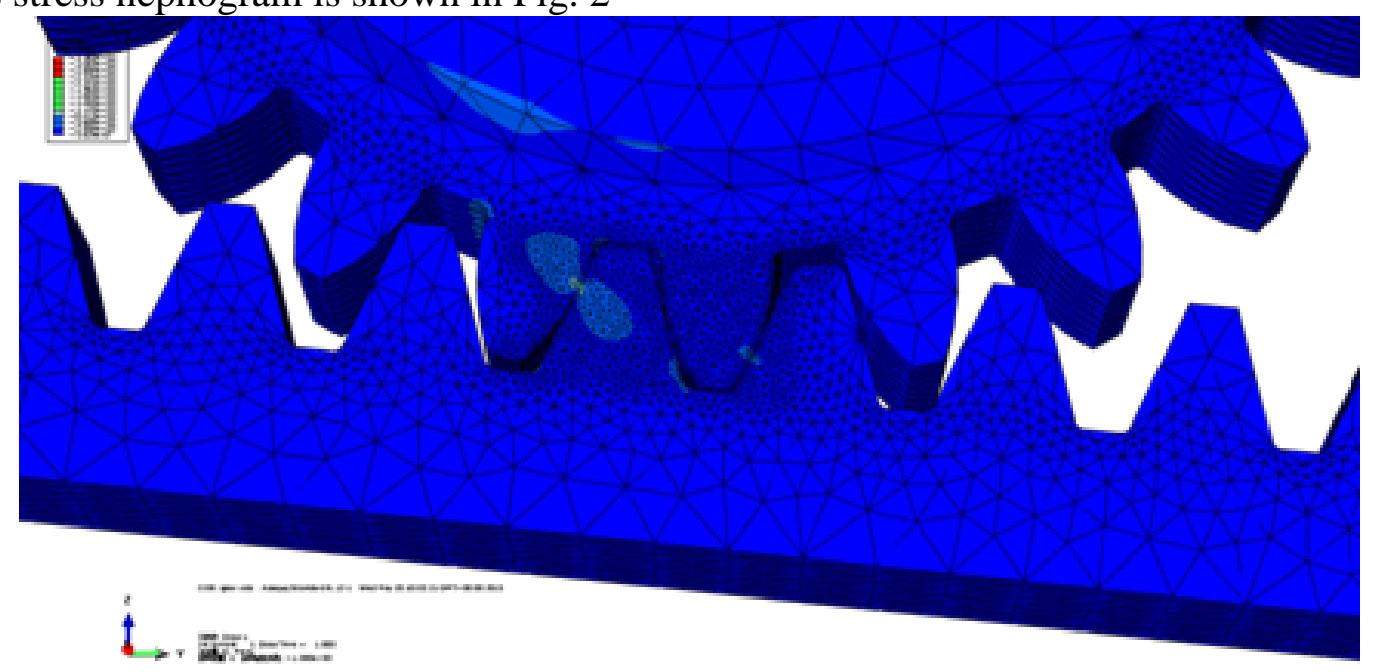

Figure 2 the Mises stress nephogram of gear rack

From the Mises stress nephogram we can see the biggest stress is generated in the contact surface and the root of tooth being $730.2 \mathrm{MPa}$, which is less than the finite stress of 835MPa.It is convincible that the contact surface bear high stress and the root of the tooth is bearing high bending load, easily causing the fatigue and spalling of contact surface.According, it is necessary to perform an analysis of reliability.

\section{Establishment of Surrogate Model by Kriging Method}

\subsection{Introduction of Kriging Method}

The Kriging method is developed by Matheron[1]based on the achievement of Krige,with a high accuracy in nonlinearity.Giunta[2]studied the problem of multi-disciplinary design optimization using Kriging method.Kaymaz[3] introduced the Kriging method into reliability analysis.

The Kriging method is composed of two parts: polynomial and random distribution.

The specific model is:

$$
y(x)=F(\beta, x)+z(x)=f^{T}(x) \beta+z(x)
$$

The $\beta$ is regression coefficient, $\mathrm{f}(\mathrm{x})$ is polynomial.In design space, $\mathrm{f}(\mathrm{x})$ offers global proximate,namely mathematical expectation;While $\mathrm{z}(\mathrm{x})$ offers local deflection proximate,namely local variation of $\mathrm{y}(\mathrm{x})$. 


\subsection{Random Variable and Performance Function}

There is no analytical expression of limit state function for the gear rack contact problem,which means the limit state function is implicit. The performance function is shown as follows based on the stress-intensity interference theory:

$$
\sigma_{s}-G(D, E, T)=\left\{\begin{array}{l}
<0 \text { failure } \\
=0 \text { limit } \\
>0 \text { reliable }
\end{array}\right.
$$

Where $\mathrm{D}$ is distance between reference circle of gear rack(mm),E is elasticity modulus(GPa), $\mathrm{T}$ is torque(NM) and $\sigma_{s}$ is yield strength(MPa).

The four variables are choosed as random variables, and obeys normal distribution,the distribution is shown as follows:

$\mathrm{D} \sim \mathrm{N}(0,0.17) \quad \mathrm{E} \sim \mathrm{N}(207,6.9) \quad \mathrm{T} \sim \mathrm{N}(200,6.67) \sim \mathrm{N}(835,28.33)$

Normally,the fitting precision will grow with the number of sample points but the calculation cost will grow simultaneously. This paper choose 18 groups of sample points.

\subsection{Calculation of Stress Response}

This paper perform an analysis of gear rack using Abaqus after sample points are obtained,FEA results of 18 groups of sample points are obtained by changing the parameters of variables,which is shown in Table 2:

Table 2 variables and response value

\begin{tabular}{cccc}
\hline $\mathrm{D}[\mathrm{mm}]$ & $\mathrm{E}[\mathrm{GPa}]$ & $\mathrm{T}[\mathrm{NM}]$ & stress[MPa] \\
\hline 0.0991 & 211.5900 & 199.79 & 736.101 \\
-0.0447 & 198.1300 & 202.39 & 745.677 \\
0.1527 & 198.3800 & 198.5475 & 731.521 \\
0.0886 & 210.3000 & 189.255 & 697.289 \\
-0.1905 & 212.3000 & 220.98 & 814.168 \\
-0.0043 & 207.9300 & 194.3725 & 716.142 \\
0.1466 & 198.5200 & 194.23 & 715.614 \\
-0.0379 & 212.3800 & 198.605 & 731.736 \\
0.0221 & 214.3100 & 191.4025 & 705.201 \\
0.0313 & 202.1800 & 203.7425 & 750.66 \\
-0.1797 & 204.7600 & 196.7375 & 724.553 \\
-0.1207 & 201.7500 & 189.07 & 696.605 \\
0.2764 & 193.9700 & 198.6775 & 731.998 \\
0.5020 & 201.6700 & 204.0275 & 751.71 \\
-0.0453 & 210.3800 & 200.8075 & 739.85 \\
-0.1357 & 206.9500 & 204.4525 & 753.277 \\
0.2175 & 207.4700 & 204.8975 & 754.917 \\
-0.2177 & 203.1100 & 187.2 & 689.716 \\
\hline
\end{tabular}

\subsection{Establishment of Kriging Model}

Choose the 18 groups of sample points and the FEA response as basic information.Because of the minor impact of polynomial $\mathrm{f}(\mathrm{x})$ to the accuracy of Kriging model,the regressor is selected as 1 .

Relevant equation is determined factor to the accuracy of model,so this paper choose the good-performed Gaussian correlation equation.

\subsection{The Verification of Kriging Model}

It is necessary to compare the FEA results with the Kriging model results after the Kriging model is established.10 groups of sample points is selected in The value space,and the results are shown in Table 3 and Fig. 3. 
Table 3 comparison between Kriging and FEA

\begin{tabular}{llllll}
\hline $\mathrm{D}[\mathrm{mm}]$ & $\mathrm{E}[\mathrm{GPa}]$ & $\mathrm{T}[\mathrm{NM}]$ & Kriging[MPa] & FEA[MPa] & error \\
-0.1341 & 198.8998 & 193.9470 & 714.3263929 & 714.572 & $3.44 \mathrm{E}-4$ \\
0.0718 & 211.3788 & 198.1070 & 729.9031455 & 729.946 & $5.87 \mathrm{E}-5$ \\
0.0110 & 201.0746 & 195.5445 & 720.4001554 & 720.458 & $8.03 \mathrm{E}-5$ \\
0.1601 & 209.9278 & 196.4487 & 723.7733095 & 723.791 & $2.44 \mathrm{E}-5$ \\
0.1555 & 215.9429 & 209.2762 & 770.6955268 & 771.051 & $4.61 \mathrm{E}-4$ \\
0.1538 & 212.3869 & 198.8159 & 732.4670427 & 732.513 & $6.27 \mathrm{E}-5$ \\
0.0670 & 197.5341 & 209.4386 & 771.6474246 & 771.644 & $4.44 \mathrm{E}-6$ \\
0.0420 & 215.8056 & 198.8815 & 732.6486995 & 732.755 & $1.45 \mathrm{E}-4$ \\
0.0495 & 205.2421 & 205.6488 & 757.7143054 & 757.684 & $4.00 \mathrm{E}-5$ \\
0.0490 & 207.8876 & 198.2804 & 730.5523406 & 730.539 & $1.83 \mathrm{E}-5$ \\
\hline
\end{tabular}

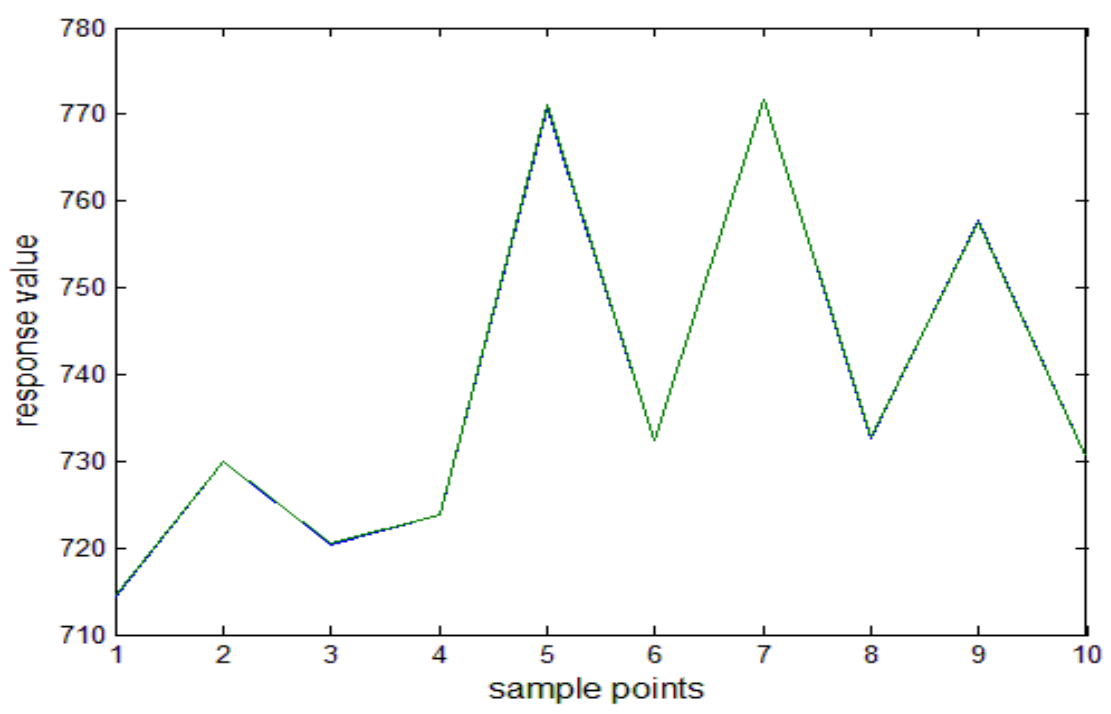

Figure 3 comparison between Kriging and FEA

The relative error between Kriging and the FEA results is in a minor scale judged From Table 3.So it is convincible that the founded Kriging model is of high accuracy.

\section{6 the Reliability Calculation of Gear Rack Contact}

Select 10000000 groups of samples to calculate the failure probability by Monte Carlo method.The failure probability is 0.004433 and the reliability is 0.995567 .

\section{Surrogate Model Establishment by Response Surface Method}

\subsection{Introduction of RSM}

The basic idea of response surface method is to approximate implicit limit state function by polynomial.The polynomial function will converge in probability to actual implicit limit state function by rational sample points and iteration strategy[4].The weighted least-squares method can raise the effect of the ideal points while reduce the effect of the non-ideal points[5].This paper utilize the nonlinear weighted response surface method to reflect the effect of nonlinearity, which is shown as follows:

$$
g(x)=b_{0}+\sum_{i=n+1}^{n} b_{i} x_{i-n}^{2}+\sum_{i=n+1}^{2 n} b_{i} x_{i-n}^{2}
$$

Where $b=\left(b_{0}, b_{1}, \ldots, b_{2 n}\right)^{T}$ is undetermined coefficient

The foundation of weight is: 


$$
\begin{aligned}
& \left\{\begin{array}{l}
g_{\text {best }}=\min _{i=1}^{m}\left|g\left(x_{i}\right)\right| \\
w_{i}=\frac{g_{\text {best }}}{\left|g\left(x_{i}\right)\right|} \quad i=1,2, \ldots, m
\end{array}\right. \\
& b=\left(a^{T} W a\right)^{-1} \times a^{T} W y
\end{aligned}
$$

Where $\mathrm{n}$ is the variable number; $\mathrm{w}$ is the weight matrix.

\section{2 the establishment of the response surface method}

Choose the 18 groups of sample points and the FEA response as basic information to calculate the coefficients of the fitting function.Then 8 groups of sample are selected to compare the relative error between the value of response surface method(RSM) and finite element analysis, which is shown in Table 4 and Fig. 4.

Table 4 comparison between RSM and FEA

\begin{tabular}{cccccc}
\hline $\mathrm{D}[\mathrm{mm}]$ & $\mathrm{E}[\mathrm{GPa}]$ & $\mathrm{T}[\mathrm{NM}]$ & $\mathrm{RSM}[\mathrm{MPa}]$ & FEA[MPa] & error \\
\hline 0.0718 & 211.3788 & 198.1070 & 729.7984832 & 729.946 & $-1.43 \mathrm{E}-04$ \\
0.0110 & 201.0746 & 195.5445 & 720.3467979 & 720.458 & $-7.41 \mathrm{E}-05$ \\
0.1601 & 209.9278 & 196.4487 & 723.7099703 & 723.791 & $-8.75 \mathrm{E}-05$ \\
0.1555 & 215.9429 & 209.2762 & 770.9768998 & 771.051 & $3.65 \mathrm{E}-04$ \\
0.1538 & 212.3869 & 198.8159 & 732.4226522 & 732.513 & $-6.06 \mathrm{E}-05$ \\
0.0670 & 197.5341 & 209.4386 & 771.5600156 & 771.644 & $-1.13 \mathrm{E}-04$ \\
0.0420 & 215.8056 & 198.8815 & 732.6364468 & 732.755 & $-1.67 \mathrm{E}-05$ \\
0.0495 & 205.2421 & 205.6488 & 757.5844784 & 757.684 & $-1.71 \mathrm{E}-04$ \\
0.0490 & 207.8876 & 198.2804 & 730.4329559 & 730.539 & $-1.63 \mathrm{E}-04$ \\
-0.1341 & 198.899 & 193.9470 & 714.4021337 & 714.572 & $1.06 \mathrm{E}-04$ \\
\hline
\end{tabular}

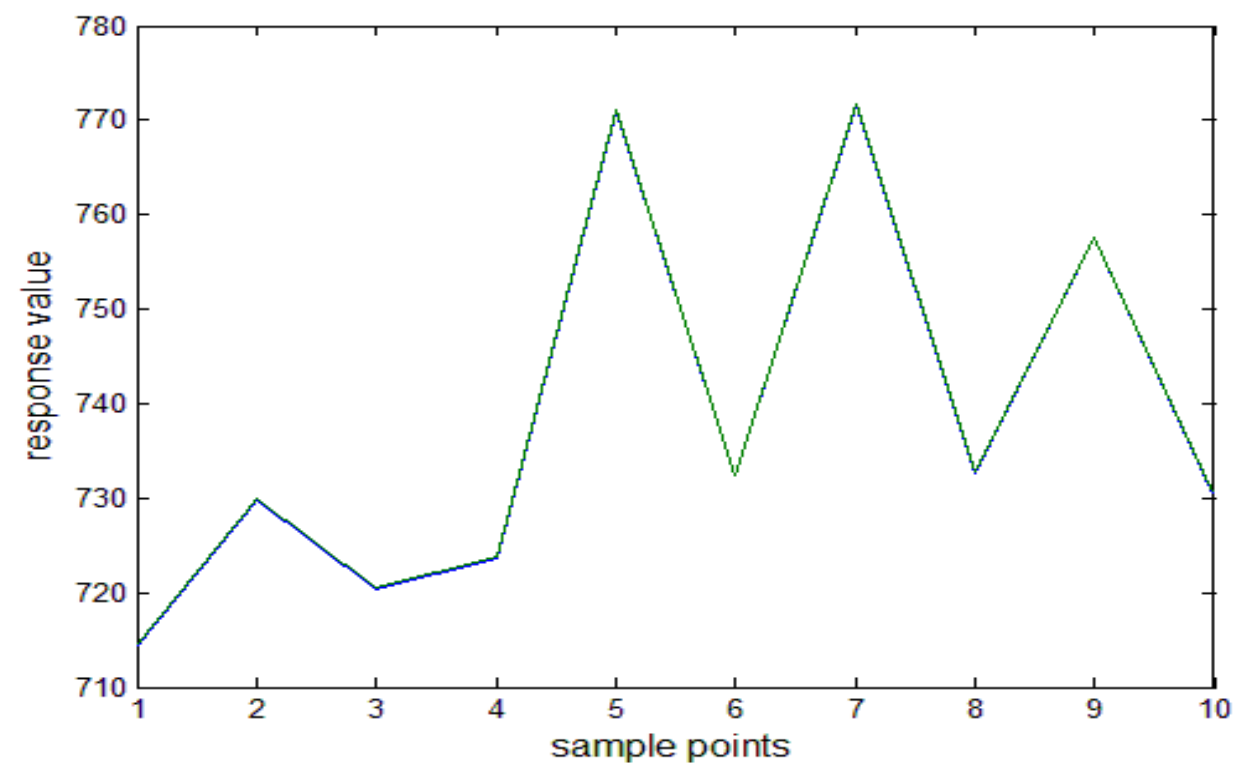

Figure 4 comparison between RSM and FEA

The relative error between RSM and the FEA results is in a minor scale judged From Table 4.So it is convincible that the founded RSM model is of high accuracy.

\section{3 the reliability calculation of gear rack contact}

Select 10000000 groups of samples to calculate the failure probability by Monte Carlo method.The failure probability is 0.004302 and the reliability is 0.995698 . 


\section{Comparison between Kriging method and RSM}

Compared to the response surface method,the Kriging method is of higher accuracy when fitting the input-output function of gear rack contact judged by the former results.Accordingly,Kriging method is more convincible when calculating the gear rack contact reliability.

The reason lies in the high nonlinearity,in which situation the Kriging method is more likely to obtain an accurate results,and owns good adaptation.

\section{Conclusions}

This paper analyzed the gear rack contact reliability by surrogate model.The main work is as follows:

(1)The contact stress under certain working condition is analyzed in abaqus.

(2)The surrogate model is founded utilizing the Kriging method and response surface method.Then the reliability is respectively calculated by Monte Carlo method.

(3)The accuracy of two surrogate models is compared and the Kriging method can reach a higher accuracy in the issue of gear rack contact.

\section{References}

[1] DU De-wen, MA Shu-zhen, CHEN Yong-liang.Overview of the methods in geology statistics [J].Journal of World Geology, 1995, 14(4):79 -84.

[2] Giunta A A. Aircraft multidisciplinary design optimi-zation using design of experiments theory and re-sponse surface modeling [D]. Blacksburg, Virginia:Virginia Polytechnic Institute and State University,1997.

[3] Kaymaz I. Application of kriging method to structur-al reliability problems [J].Structural Safety,2005,27(2):133 -151.

[4] Lv Zhen zhou.Reliability and sensitivity analysis of structure and mechanism[M].Beijing:Science Press.2009.

[5] Zhao Jie.Study of response surface method in mechanism reliability analysis[D].Xi'an:Northwest Polytechnical University.2006 